\author{
ELISA VARGASLU GO
}

\title{
El indio que tenía "el don..."
}

$\mathrm{N}$

arra el padre César Fel ipe Doria S. J., biógrafo del padre Juan M aría de Salvatierra, ${ }^{1}$ que la madre del príncipe Doria, Violante Lomelina, le había dado gran apoyo para que él pudiera seguir su vocación religiosa, lo cual produjo un fuerte lazo afectivo entre ambos personajes. Una vez ordenado, el padre Salvatierra fue invitado por esa señora y por su nuera, la princesa Pánfila, a celebrar misa en el oratorio de su palacio. A esa invitación acudió Salvatierra acompañado por su amigo y correligionario Juan Bautista Zappa (1651-1694). D e ahí en adelante las princesas D oria estrecharon aún más su amistad con esos jóvenes jesuitas que estaban a punto de salir hacia las misiones de América. Esto sucedía antes de 1675, año en que el padre Zappa llegó a la N ueva España.

La historia narra que a la Virgen de G uadalupe de M éxico atribuyeron, los devotos padres Salvatierra y Zappa, el hecho de que los hubieran escogido a ellos para salir a laborar en las Indias. Seguramente el culto a la Virgen de Guadalupe de M éxico fue motivo central en las conversaciones sostenidas entre los jóvenes jesuitas y las princesas $D$ oria, puesto que doña Violante Lomelina pidió al padre Zappa que, una vez que se encontrara en la N ueva España, y en cuanto le fuera posible, le enviara una copia de la famosa imagen de la "Virgen de Guadalupe", ${ }^{2}$ encargo que el sacerdote cumplió con todo interés y la prontitud que le permitieron las circunstancias.

1. Alfonso René Gutiérrez, edición crítica de la Vida del V. P. Juan M aría de Salvatierra escrita por el V. P. César Felipe D oria, M éxico, C.A. y Fondo Regional para la Cultura y las Artes del N oroeste, 1997.

2. I bidem, pp. 15-18. 
Este interesante episodio acerca de la fama universal que había al canzado el culto guadalupano en Europa se encuentra referido con todo detalle en un manuscrito - aparentemente aún inédito - sobre la vida del padre Juan Bautista Zappa, escrito precisamente por su gran amigo y compañero el padre Juan M aría Salvatierra. ${ }^{3}$ En síntesis, la historia es la siguiente:

Cuando el padre Zappa se embarcó para el N uevo M undo - junto con un compañero de su comunidad- , tuvo la buena suerte de que en el mismo viajara el padre rector de la Compañía de Jesús, don Pablo de Salzedo (o Salcedo). Además, dio la casualidad de que otro fraile, que viajaba también hacia América, tenía que entregarle a dicho rector "unas pocas doblas que le habían sobrado del viaje de Italia a las Indias [... ]" Se deduce del texto que el padre Zappa aprovechó esta circunstancia para pedir al padre rector - quien también era muy devoto de la Virgen de Guadalupe - que ayudase con dichas doblas para el costo de la copia del lienzo guadalupano. El padre Salzedo aceptó desde luego colaborar para la compra de la pintura tan esperada en G énova, puesto que él sabía que eran "muy costosas en M éxico semejantes pinturas", ${ }^{4}$ y que posiblemente el padre Zappa no contara con la suma necesaria. Pero lo más importante es que el padre Salzedo le recomendó al padre Zappa y a su compañero que, para adquirir dicha copia, "fuesen a ver las veces que se necesitase al indio pintor [... ] que fuesen a la casa del indio que tenía el don de pintar a la Virgen de Guadalupe".

El padre Zappa tomó muy en cuenta esas palabras a pesar de que, al llegar a la ciudad de M éxico, se enteró de que "H avía en la ocasión, en M éxico, pintores españoles de bastantes créditos. Y M anuel (sic) Correa, [seguramente se refería a Juan Correa] en materia de copias tenía el aplauso de todos los españoles, que a una voz dezían podía parecer en españa (sic) sus copias y con aplauso del pintor indiano". Como ha quedado aclarado en los estudios que se han hecho en tiempos recientes sobre la obra de Juan Correa ${ }^{5}$ - por

3. “Vida del P. Zappa escrita por el P. Juan M aría Salvatierra”. mss, agn, Legajo núm. 6, Le tras Y y B. C on 383 folios sin numerar. Lleva una nota que dice: D e la Librería de la Purísima. Agradezco al licenciado J osé M aría Lorenzo, becario del sn i, la localización de este documento.

4. I dem.

5. Ante todo hay que aclarar que no existió un pintor de apellido Correa que se llamara $M$ anuel. O bviamente el padre Salvatierra se equivocó al Ilamarlo así. Tal como informó su discípulo José de I barra, Juan Correa poseyó una calca de la imagen guadalupana original que le permitió hacer numerosas reproducciones de la misma, que fueron muy admiradas y muy nu- 
cierto, persona de origen mulato y no español, como creyó el padre Salvatierra- , éste ha pasado a la historia como el pintor, por excelencia, de la Virgen de Guadalupe a lo largo de la segunda mitad del siglo xvii, como lo demuestran tantas obras suyas con este tema. Pinturas, en efecto, de primera calidad, que se admiran a la fecha en diversas ciudades de M éxico y de España, muy apreciadas y costosas en la actualidad.

El padre Salvatierra afirma en su escrito que todo M éxico "está lleno de imágenes de la V irgen de Guadalupe... [y del todo convencido, añade] y raras son las que se parecen al original [?] y es corriente entre todos los pintores así españoles como indios que solo el indio que tiene el don pinta con más semejanza esta Señora [... ]" y además les concede a los lienzos del indio la cualidad de poseer el D on curationum - y continúa - "siendo assy que las demás copias no llevan tanto a la devoción como las copias por mano del indio que tiene el Don [... ]"6

Enseguida, el padre Salvatierra proporciona la muy importante noticia siguiente para la historia del arte guadalupano:

quando muere el indio pintor mexicano que tiene el $D$ on de pintar, se juntan todos los mexicanos pintores ${ }^{7}$ y van todos con devoción a Guadalupe, confiesan todos y comulgan y después delante de la cacita [sic] del Tepeyac pintan todos a la Señora, así Ilamada por ellos [... ] y acabadas todos sus pinturas ellos son los jueces de decir quien es el indio que recibió el $D$ on de pintar con más imitación la verdadera imagen. Cotejándolas todas, a éste le daban el paravien y avisan a la ciudad y se acudía a él de los que quieren la mayor semejanza de la pintura. En este tiempo tenía el $\mathrm{D}$ on de pintar un indio llamado D on Luis deTexeda [... ]

justamente cuando el padre Zappa buscaba una copia para enviarla a la familia D oria.

Fue el padre Zappa en busca de ese indio que vivía en un arrabal de la ciudad de M éxico y conchavó [sic] el precio, pero tuvo que regresar varias ve-

merosas, y muchas de las cuales se encuentran aún en España. Al parecer, el padre Zappa no se enteró de que el pintor guadalupano Juan Correa no fue ni español ni criollo, sino mulato.

6. Juan M aría de Salvatierra, op. cit., s.f.

7. Esta frase permite suponer que el concurso entre pintores indios para representar a la Virgen de Guadalupe era ya costumbre arraigada entre ellos, de al gún tiempo atrás. 
ces al xacal [sic] del indio porque éste, a causa de tener muchos encargos, retrasaba la entrega.

No ha sido posible averiguar cuándo exactamente Zappa obtuvo la deseada pintura, ni cuánto tiempo tomó a ésta llegar a Génova, pero con seguridad en cuanto el padre recibió el lienzo firmado por el indio don Luis de Texeda lo remitió a Génova bien encajonado y tuvo la posibilidad de darlo en custodia a un correligionario que viajaba a Italia. Afortunadamente, la flota no sufrió ningún contratiempo durante la travesía y la pintura llegó bien a manos de la princesa Doria, quien la acogió en su palacio con mucha "solemnidad y devoción". ${ }^{8} \mathrm{H}$ ubiera sido interesante saber cuánto tiempo esperó el padre Zappa para conseguir la pintura, con objeto de tener una idea del ritmo de trabajo del pintor indio. Lo que es seguro es que la imagen tuvo que haber llegado o bien a finales de 1647 o en los primeros meses del año de 1684, dado el siguiente suceso. ${ }^{9}$

Al decir del padre Salvatierra, muy pronto el palacio Doria recibió de manera patente la protección de la G uadalupana, cuando - entre el 17 y el 20 del mes de marzo de 1684- el rey de Francia, Luis XIV, atacó la ciudad de G énova, como represalia porque ésta se inclinó hacia España, nación que era adversaria de Francia. D e ese ataque y de los "bombeos" - que destruyeron "Io mejor de la ciudad Palacio de la República e iglesias" - ${ }^{10}$ se salvó el palacio D oria, a pesar de que "Está situado [... ] fuera de la ciudad vieja, inmediata a la playa del mar [... ] y [... ] quien estaba mas espuesto a la total ruina era el palacio donde el príncipe D oria". ${ }^{11}$ Las princesas Pánfila, esposa del príncipe Andrea, y su madre, V iolante Lomelina, buscaron la protección divina mediante sus oraciones, pero, además, salieron en procesión "con toda su corte y vecindad", 12 recorriendo en círculo el edificio "llevando por escudo y defensa la Señora de Guadalupe y cantando las letanías lauretanas", ${ }^{13}$ procesión que necesariamente debió haber sido hecha con suntuosi-

8. Idem.

9. Si el padre Zappa se embarcó para M éxico en 1675 y el milagro guadalupano tuvo lugar en 1684, mediaron cerca de nueve años entre que se hizo y logró el encargo y que la imagen llegó a manos de las princesas $D$ oria.

10. Alfonso René Gutiérrez, op. cit. N oticia tomada de una carta de la princesa Lomelina al padre Salvatierra según informa el autor.

11. Juan M aría de Salvatierra, op. cit.

12. I dem.

13. Idem. 
1. Luis D etegeda, Virgen de Guadalupe, $m$. fecit 1669. Museo Nacional de Historia, Chapultepec. Foto: M aricela González C ruz M anjarrez, Archivo Fotográfico iie-unam.

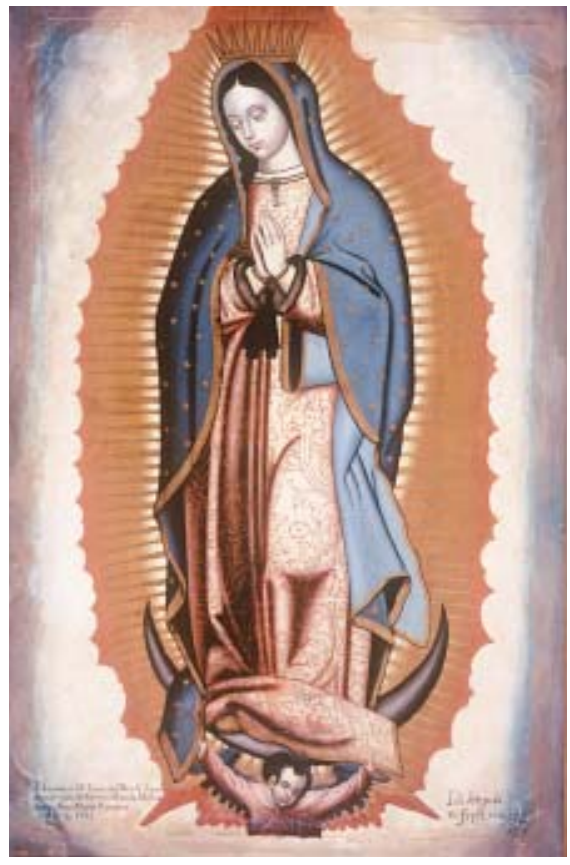

dad deslumbrante. D e esta manera espectacular, la Virgen de Guadalupe de $M$ éxico hizo su primer milagro en G énova, ${ }^{14}$ evitando todo daño al palacio de la familia D oria.

Por lo tanto transcurrieron prácticamente nueve años entre 1675, cuando el padre Juan Bautista Zappa llegó a la ciudad de M éxico, ordenó la copia, la obtuvo y preparó el envío a G énova, y la fecha en que finalmente la imagen de la "Virgen de Guadalupe" llegó a manos de las princesas Doria. Este cálculo de tiempo se ve confirmado por la información obtenida en Italia, como se verá enseguida.

Para tratar de averiguar el posible paradero de esa pintura enviada a la familia D oria escribí cartas a varios museos de Italia. ${ }^{15} \mathrm{H}$ acia finales de 2000 contes-

14. Idem.

15. Agradezco mucho a la doctora Clara Bargellini que se haya molestado en escribir esas cartas en italiano. 
tó la doctora Stefanía di M arco, del M useo Arti D oria Pamphily de G énova, para informar que, tristemente, la pintura ya no estaba en su galería, pero que en los inventarios del Palacio sí hay noticia de ella en $1684^{16}$ (precisamente el año en que tuvo lugar el ataque de los franceses a $G$ énova) y me remitió a la doctora Laura Stagno, de la misma institución, quien después de varios meses confirmó que la pintura efectivamente está documentada en el palacio del Príncipe D oria, en el siglo xvii, cuando se hicieron los arreglos "del departamento", pero que actualmente el lienzo no se encuentra allí y no se sabe si fue vendido o cedido; añadió que en los mismos documentos del archivo consta la gran devoción que la princesa $V$ iolante Lomelina $\mathrm{D}$ oria profesaba a esa imagen.

Empero, si la investigación en Italia resultó infructuosa no lo fue en M éxico, pues por lo menos se han localizado los dos lienzos de los que había alguna información, creaciones del indio que tuvo "el don": don Luis detexe da o detegeda, como él indistintamente firmaba.

El lienzo más antiguo se localiza en el M useo de H istoria de Chapultepec y está firmado "Luis detegeda m. fecit. 1669"; en el ángulo inferior derecho y en el ángulo opuesto, dice: "A devoción de doña Juana de Dios Cliseria se puso esta vidriera, siendo M allordomo Ana M aría Ramírez. Año de 1793." El segundo lienzo se encuentra celosamente cuidado en el Santo Desierto de Tenancingo ${ }^{17}$ de los frailes carmelitas. La firma, aunque algo borrosa, se puede leer en el ángulo inferior derecho y dice: "D. Luis detexeda 1682", y no 1632, como registró el desaparecido maestro Xavier M oyssén, como se aclara en el siguiente párrafo.

En el contenido de una nota a pie de página, correspondiente al capítulo $V$ de la Pintura colonial en $M$ éxico, ${ }^{18}$ obra de $M$ anuel Toussaint anotada precisamente por Xavier M oyssén, Toussaint dejó escrito que el pintor español $\mathrm{N}$ icolás de Tejeda ${ }^{19}$ debió haber llegado a la N ueva España desde mediados

16. Este dato es de importancia porque confirma que la Virgen de Guadalupe ya estaba ciertamente en $\mathrm{G}$ énova ese año del ataque de los franceses.

17. Agustín Velázquez Chávez dejó registrada esta pintura en su libro Tres siglos de pintura colonial en M éxico, Polis, 1936. Agradezco a la comunidad carmelita y en especial al padre Carlos $M$ artínez las facilidades que me dieron para fotografiar la pintura.

18. M anuel Toussaint, Pintura colonial en M éxico, M éxico, Universidad Nacional Autónoma de M éxico, 1965.

19. Este artista fue quien pintó los dos encerados, con las imágenes de san Pedro y san Pablo 
del siglo xvi. El maestro M oyssén ${ }^{20}$ concluyó al respecto que: "Junto a $\mathrm{N}$ icolás de Texeda hay que anotar a Luis de Texeda de quien existe un cuadro en el $D$ esierto deTenancingo, firmado y fechado en 1632; es curiosa esta pintura por ser la primera copia del célebre lienzo, firmada y fechada, de quien se tiene noticia." Pero, conocida ahora la filiación indígena del pintor Luis D etexeda y aclarado que la fecha de este lienzo es 1682 y no 1632, quedan desmentidas las suposiciones de Moyssén, tanto en cuanto a que Luis de Texeda hubiera sido español llegado a la Nueva España a mediados del siglo xvi y posiblemente relacionado con N icolás de Tejeda, como que la "Virgen de Guadalupe" de Tenancingo hubiera sido la copia más antigua fechada. ${ }^{21}$ Lo que sí es un hecho es que esta pintura es, por el momento, la de fecha más antigua que se conoce firmada y fechada por un artista indígena bien identificado.

\section{Algo acerca del concurso}

Aunque existen muchas copias de la "Virgen de Guadalupe" que por su oficio de carácter local o porque presentan sumamente moreno el rostro de la "Señora" pueden considerarse creaciones de pintores indígenas, no se conoce la identidad de ellos ni hay manera de relacionarlos con el concurso. Por el momento - se repite- las obras de don Luis de Texeda son las únicas creaciones guadal upanas firmadas por un artista indio poseedor del don...

Por otra parte, dada la manera como hablan los textos del concurso de pintura guadalupana entre pintores indígenas, es evidente que dicho certamen ya debía tener muchos años de celebrarse. No puede negarse que se habla de ello como de una práctica consabida. Por eso el padre Salzedo decididamente recomendó al padre Zappa que encargara la copia de la "Virgen de Guadalupe" al indio pintor que ese año tenía el don. Es más, en aquella

que se colocaron en los óculos que tenía la portada de la antigua catedral de M éxico. Esas obras, según consideró el maestro Toussaint, se pintaron hacia 1585.

20. M anuel Toussaint, op. cit., p. 249.

21. Por mucho años la copia de la "Virgen de Guadalupe" con fecha más antigua fue la que se conserva en el Santo D esierto de San Luis Potosí, que lleva inscrito el año de 1635, firmada por Lorenzo D elapyedra. Pero cuando el Centro Cultural de Arte Contemporáneo organizó la exposición "I mágenes guadalupanas. Cuatro siglos" se encontró la pintura firmada por Baltasar de Echave 0 rio en 1606 . A la fecha, ésta sigue siendo la copia más antigua. 
mitad del siglo xvii el concurso pareciera ser ya un acontecimiento ampliamente reconocido por la sociedad, y desde luego por los religiosos, pero no es posible aún proponer una fecha aproximada de su inicio.

Sin embargo, dos noticias más ponen de manifiesto la fama adquirida por el concurso y son las siguientes:

La primera, aunque sin fecha, puede considerarse un comentario hecho en algún momento durante los nueve años transcurridos entre 1675 y 1684, cuando el padre Zappa actuó como emisario de las princesas D oria, y se encuentra en una de las copias anónimas de la biografía que el padre Salvatierra escribió sobre la vida del padre Zappa, donde se dice:

Y para que no haga novedad para los que vieren esta historia debe advertirse que es experiencia bien notada de todos políticos y ( $r$ [eligiosos?]) literatos e indoctos de estos reinos que la Señora de Guadalupe sólo se permite espiar con [viveza] de mano de los indios aunque no son estas de ordinario las más ágiles para manejar los pinceles, pero en materia de trasuntar aquesta santa imagen, es cierto que les dan públicamente la ventaja [a] los pintores españoles, aun los más afamados en este arte. $Y$ aun entre los indios el que con más perfección saca la copia de su belleza es el que dicen ellos que tiene el don de pintarla. ${ }^{22}$

Como ya quedó dicho arriba, si se habla del concurso como de una experiencia bien notada por la sociedad, puede ser que el certamen se hubiera instituido desde el siglo xvi.

La segunda información se encuentra en el apartado titulado "Refiérense algunos otros casos milagrosos de esta prodigiosa imagen", comprendido en la conocida obra Zodiaco mariano del padre Francisco de Florencia S.J..$^{23} \mathrm{Se}$ trata del testimonio de un suceso milagroso que fue enviado en 1691 por el padre Joseph de Tapia al padre Florencia, porque notó que éste no lo había incluido en su historia de la Virgen de Guadalupe. Recogió el padre Florencia ese relato y después lo publicó en su Zodiaco mariano. El extraordinario caso consistió en que, luego de haber tenido diferencias, el virrey duque de Albuquerque y el arzobispo de M éxico, M atheo Saga de Bugueiro, decidie-

22. "Vida del padre Juan Bautista Zappa”. agn , mss: Anónimo. Ramo de H istoria, vol. 285, f. 209r. Este manuscrito es una segunda versión del anteriormente citado.

23. Francisco de Florencia y Antonio de O viedo, Zodiaco mariano, M éxico, Consejo N acional para la Cultura y las Artes, 1995, pp. 101-102. 
ron hacer las paces y confirmarlas ante la imagen de la $V$ irgen de G uadalupe en 1658:

para lo cual descubrieron la imagen quitándole la vidriera. $\mathrm{H}$ abía entonces un indio muy cristiano y excelente pintor a quien Dios había dado gracia especial para copiar vivamente la sagrada imagen. Llamáronlo por eso, para que viéndola más de cerca y sin vidriera pudiera, con más acierto hacer dos retratos, uno para el señor virrey y otro para el señor arzobispo. Vino llamado el indio pintor, pero al llegarse cerca de la imagen sintió que se le espeluznaban los cabellos y que le temblaba todo el cuerpo, y lo más prodigioso fue que no veía la imagen, sino solamente el ayate 0 tilma en que está la imagen formada. Con esto se retiró sin tratar por entonces las copias que le pedían. ${ }^{24}$

Respecto al informante, el padre Florencia comenta que no se podía dudar de "la verdad e ingenuidad del padre Tapia, sujeto muy acreditado en esta provincia" y para concluir dejó asentada esta frase: "Y como fue gran milagro el pintarse la señora en el ayate, no fue menor el despintarse. Ella sólo sabe lo que les quiso decir al virrey y al arzobispo con un suceso tan raro y prodigioso."

D e este suceso se deduce que cuando menos 17 años atrás del tiempo en que el padre Zappa visitaba al pintor indio Luis de Texeda, es decir, hacia 1641, ya se celebraba el concurso.

\section{Luis D etexeda y Juan Correa}

Tratándose de la abundante pintura guadalupana que se produjo en la segunda mitad del siglo xvii, no es posible soslayar el papel preponderante que en ese campo tuvo el artista mulato Juan Correa, como el pintor guadalupano "por excelencia". ${ }^{25}$ Así pues, no fue de ninguna manera casual que el padre Zappa hubiera sido informado de la existencia de un pintor de apellido Correa, famoso por sus copias de la V irgen del Tepeyac.

24. Idem.

25. C fr. Elisa Vargaslugo y José Guadalupe Victoria, Juan Correa. Su vida y su obra, t. IV, Repertorio pictórico, 2 tomos, M éxico, U niversidad N acional Autónoma de M éxico, 1994. 
Juan Correa firma su primera Guadalupana en $1667^{26}$ y la obra más temprana de Texeda - hasta ahora conocida - es de 1669, así que, a pesar de la posible diferencia de edades, estuvieron activos dentro de la misma generación y, dado su "guadalupanismo", seguramente se conocieron. Sin embargo, no son del todo iguales las interpretaciones de cada uno de ellos, no obstante que el tema pictórico, claro está, no permitía alteraciones.

El espíritu religioso, la privilegiada devoción guadalupana y el éxito como pintor de esa especialidad pictórica no fueron características exclusivas del indio que tenía el don. También Juan Correa, a pesar de no haber sido indio sino mulato, se distinguió por su profesionalismo pictórico y su devoción por la Virgen de Guadalupe, heredada de su padre. ${ }^{27}$

O bviamente, las imágenes guadalupanas pintadas por Juan Correa - 0 por Luis de Texeda, o por cualquier otro pintor, en los tiempos de la N ueva España - son reproducciones fieles del modelo original y sólo podrían señalarse algunas mínimas o sutiles diferencias, entre unas y otras como el color 0 los trazos de las facciones del rostro. Lo que puede resultar diferente en algunos casos es "el espíritu" o "aliento" que el pintor imprimió a su obra, mediante mayor o menor luminosidad, ya sea en el rostro 0 en toda la composición. Por ejemplo, si la Virgen tiene el rostro muy moreno o, al contrario, es casi blanco, o si el colorido general es más claro o es de tonos más sobrios, el efecto pictórico será distinto para el espectador, sin que, por supuesto, se den cambios en la significación religiosa. En las obras de Correa, que por cierto son muchas, ${ }^{28}$ puede decirse que el tono general es producto de una paleta más clara, más transparente que la de Texeda, lo que sin dejar de ser de vivo colorido parece tener más espesor en la capa pictórica. Por supuesto, ambos artistas pusieron sumo cuidado en reproducir las veladuras

26. Esta obra, citada por M ariano Fernández de Echeverría y Veytia en su obra "Baluartes de M éxico. Relación histórica de las Q uatro milagrosas I mágenes de N uestra Señora... ", mss s.f., ca. 1778, fue localizada por Elisa Vargaslugo en el M useo de Escultura (antes Ilamado de la Sangre) en la ciudad de Valladolid. Actualmente se encuentra perfectamente restaurada y formó parte de las colecciones que vinieron a M éxico con la exposición sobre la época de Carlos V.

27. Elisa Vargaslugo y José Guadalupe Victoria, op. cit., p. 274. El padre franciscano Francisco Frutos encargó a Juan Correa una Virgen de Guadalupe pintada sobre una concha de abulón que puede considerarse una de sus obras más entrañables en este género.

28. Se conocen por lo menos veinticinco, de las cuales puede decirse que la mitad se acompañan de las Apariciones o del paisaje de la V illa de Guadalupe. 
2. Luis D etexeda, Virgen de Guadalupe, 1682. Santo D esierto de Tenancingo, Estado de M éxico. Foto: Elisa Vargaslugo.

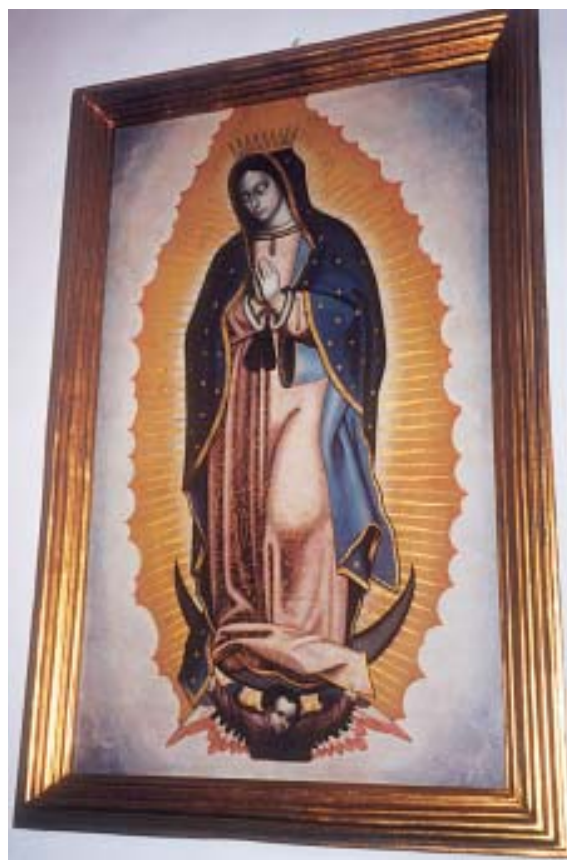

que matizan las facciones de la modelo, pero sí existe una diferencia - podría decirse de tono- entre las pinturas de ambos, que permite reconocer la obra de cada uno. Las copias de Texeda no se pueden confundir con las de $\mathrm{C}_{0}$ rrea, como podría suceder respecto a otras pinturas.

D e las pinturas de Texeda emana lo que puede ser más unción, y más carácter personal. El hecho de que estas dos obras del indio que tenía el don sean idénticas no es cosa que se explique únicamente porque se trate del mismo tema, sino resultado de un esmero muy particular, surgido - considero, sin conocer más obras de él- del espíritu místico que lo llevó a merecer que se le reconociera el "don". Pocas veces se encuentra tan completa semejanza en obras de un mismo autor. Lo que, por otra parte, permite suponer que este artista se sirvió de su propia calca, como lo hizo Juan Correa, de quien se sabe de cierto ${ }^{29}$ que le fue permitido hacerla y que la empleaba, aunque sus

29. M iguel Cabrera, Maravilla americana y conjunto de raras maravillas..., M éxico, 1756, edición facsimilar, M éxico, Jus, 1977, pp. 10-11. 
DOI: http://dx.doi.org/10.22201/iie.18703062e.2005.86.2407

$2 \mathrm{I} 4$

creaciones no son todas tan parecidas entre sí. ${ }^{30}$ No parecería lógico que "el indio que tenía el don" necesitara sacar una calca del lienzo original, pero lo que pudo haber sucedido es que, después de haber obtenido el reconocimiento de su habilidad excepcional para "trasuntar" la imagen de la V irgen, se sintiera obligado a mantener la misma calidad y expresión en cada obra, para que fueran idénticas a la premiada. Por su parte, Juan Correa no necesitaba mantener tanta exactitud entre todas sus guadalupanas. D on Luis de Texeda, en cambio, estaba obligado a mantener su sello personal e inconfundible.

En estas pinturas de Luis de Texeda, el rostro de la V irgen es especialmente fino, más fino, podría decirse, que el de la imagen original; compárese, si no, el trazo de los labios notoriamente menos carnosos que en la pintura del Tepeyac, con la que guarda semejanza sobre todo en el tratamiento de los párpados. Las líneas de las cejas, el trazo de la nariz y la diminuta boca delatan un alarde de devotísimo perfeccionismo. El color "moreno" del rostro presenta el mismo tono "plomizo" 31 que tiene el rostro de la imagen original y que abunda en muchas otras representaciones de los siglos xvii y xviii, y que no es en realidad color moreno. Compárese si no con el rostro - efectivamente moreno- deJuan Diego, cuando aparece con ella. ${ }^{32}$

30. H ay que reconocer que Juan Correa tuvo un taller importante y que las manos de sus oficiales se encuentran en prácticamente todas sus obras.

31. He preguntado a algunos restauradores si dicho tono plomizo se debe a la oxidación de las pinturas, pero aún no se ha estudiado este aspecto. Pudiera ser el resultado químico del intento de pintar un rostro moreno, pero menos moreno que el color real de los indios.

32. Acerca del color del rostro de la Virgen de Guadalupe de M éxico, vale la pena hacer los siguientes comentarios. Existía desde luego la aceptación general de que su rostro era moreno como el de los indios, pero a la vez se encuentran comentarios que demuestran la pretensión de que no fuera tan moreno, sino un poco menos. Sin duda el peculiar tono "plomizo" que se encuentra en muchas copias de la Guadalupana, a lo largo de los siglos xvii y xviii, fue el resultado de la búsqueda para conseguir un tono de moreno claro, y, cuando hubo necesidad de referirse a él, se acuñaron frases como las siguientes. Por ejemplo, en un texto del padre jesuita Andrés Pérez de Rivas (1575-1655), de 1654, se dice que la imagen "es su estatura seis palmos y un geme, el rostro muy devoto [... ] y grave, el color trigueño nevado", calificativo que trascendió al siglo xviii y que se encuentra empleado en el verso número 732 del larguísimo poema que escribió José Lucas Anaya sobre las apariciones de la Virgen de Guadalupe, en donde se lee: "Pues todo el rostro tira a lo trigueño / con no sé qué candor que dio la nieve [... ]" C fr. anónimo, Historia de la ciudad de M éxico, sacadas de la historia manuscrita de la Compañía de Jesús de la N ueva España que por el año de 1654 escribió el padre Andrés de Rivas, provincial de dicha provincia y natural de Córdoba, agn, Ramo de Historia, vol. 14, y José Lucas Anaya, La 
El tratamiento que don Luis de Texeda dio a los paños presenta líneas bien marcadas y secciones voluminosas que dan solidez a los pliegues que a su vez construyen la figura. Los paños en su consabida disposición, más que caer, "están quietos", sin ser acartonados; son consistentes, se "palpan" gruesos y están perfectamente dibujados y policromados. Al parecer los adornos de los puños de la túnica, que en la imagen original - en mi opiniónparecen conservar apariencia de bordados hechos con plumón, ${ }^{33}$ en estas pinturas parecen imitar piel animal.

La mandorla formada por los rayos solares es de vivo color anaranjado, un poco más intenso que en otras representaciones. De la figura de la Virgen emana la consabida intensa luminosidad que se combina con la que procede de la nubosidad del ambiente, y en todo salta a la vista la consistencia de la capa pictórica, que está bien conservada en ambas pinturas. Como quedó dicho, en la obra de Texeda se ve una capa pictórica más espesa, más trabajada que en las pinturas de Juan Correa, que luce una policromía más clara. D esde este punto de vista, no es posible confundir una "Virgen de G uadalupe" del indio pintor con las que pintó el artista mulato.

En suma, lo que también podría señalarse como carácter diferenciado en estas Guadalupanas de don Luis de Texeda es que más que copias pueden considerarse - con todas las salvedades del caso- "recreaciones", hasta donde le fue permitida una intervención personal.

Con seguridad, una imagen de la V irgen de Guadalupe del todo similar a las que aquí se ilustran fue la que el padre Zappa envió a la princesa D oria, quien vio así cumplido el anhelo de poseer una imagen de la "Concepción en traje de mexicana", expresión que según aclaró el padre Francisco de Florencia, ${ }^{34}$ quien se encontraba en Roma en 1668 , significaba que M aría se presentaba con el col or moreno de lasindias. \&

milagrosa aparición de N uestra Señora M aría de Guadalupe de M éxico, estudio, ed. y notas de Alejandro G onzález Acosta, M éxico, U niversidad N acional Autónoma de M éxico, 1995.

33. Recuérdese el uso tan exclusivo que se daba a las plumas preciosas en el mundo mexica, que sólo podían ser usadas y lucidas por la realeza.

34. Juan M aría de Salvatierra S.J., op. cit., s.f. 